\title{
Fatigue Performance of an Injection Molded Talc-Filled Polypropylene
}

\author{
Yuanxin Zhou, P.K. Mallick \\ Center for Lightweighting Automotive Materials and Processing, University of Michigan-Dearborn, \\ Dearborn, Michigan 48128
}

\begin{abstract}
This paper reports the fatigue behavior of an injection molded $40 \mathrm{wt} \%$ talc-filled polypropylene. The effects of specimen orientation relative to the flow direction, weld line, hole stress concentration and test frequency on the fatigue performance of this material have been considered. The fatigue strength in the flow direction was higher than that normal to the flow direction. However the orientation effect decreased at lower fatigue stress level. The presence of weld line reduced the fatigue strength. On the other hand, the fatigue strength showed very little sensitivity to the presence of hole stress concentration. The failure mode in fatigue was influenced by the test frequency. When the test frequency was less than or equal to $2 \mathrm{~Hz}$, the failure mode of the talc-filled polypropylene was due to fatigue and the fatigue life increased with frequency. However, when the test frequency was greater than or equal to $5 \mathrm{~Hz}$, the failure of the talc-filled polypropylene was due to thermal softening and the fatigue life did not appear to be influenced much by the frequency. POLYM. ENG. SCI., 45:510-516, 2005. () 2005 Society of Plastics Engineers
\end{abstract}

\section{INTRODUCTION}

During the past several years, both unfilled and filled thermoplastic polymers have found increasing number of applications in structures that are subjected to cyclic or fatigue loading. Many of these structures may experience low amplitude vibrations over extended periods of time, and are therefore prone to unexpected fatigue failure in service. Since fatigue failure is a major concern in designing these structures, it is important to establish the fatigue properties of polymers to be used in these structures.

In this paper, we will present the results of a fatigue study conducted on an injection molded talc-filled polypropylene. The purpose of this study was to consider the effects of flow-induced filler orientation, weld line, stress concentration, and test frequency on the fatigue performance of this

Correspondence to: P. K. Mallick; e-mail: pkm@umich.edu Contract grant sponsors: Ford Motor Company University Research Program, TRW Education Foundation.

DOI 10.1002/pen.20284

Published online in Wiley InterScience (www.interscience.wiley. com).

(C) 2005 Society of Plastics Engineers material. Polypropylene is a relatively inexpensive engineering thermoplastic and has many potential applications in automobiles [1], appliances, and other commercial products. It is often combined with talc fillers to improve or adjust its modulus, creep resistance, and impact strength. Static tensile properties of talc-filled polypropylene have been studied in the past by several investigators [2-4]; however, its fatigue properties are not well known.

Flow-induced filler orientation and weld lines are unavoidable facets of the injection molding process. Flowinduced filler orientation manifests in higher tensile properties in the direction of flow compared to those normal to the direction of flow. Weld lines are formed when two or more flow fronts join as the liquid polymer fills the injection mold cavity. In general, the tensile strength of the material in the welded zone is lower than the nominal tensile strength of the material. Although several studies have been conducted to understand the mechanism of weld line formation and the static strength of weld lines [5-7], there are not many reported studies on the fatigue performance of weld lines. One of these studies was by Boukhili et al. [8], in which static and fatigue characteristics of injection molded glass fiber reinforced polycarbonate were considered. In this study, a large reduction in fatigue life was observed over the whole range of fatigue stress amplitudes considered.

The effect of stress concentration on the fatigue life of polymers has been studied only to a limited extent. As expected, the general effect of the presence of stress concentration is to reduce the fatigue life. For example, Wolf and Diboll [9] observed that the fatigue strength of polyoxymethylene was a direct function of the theoretical stress concentration factor. Crawford and Benham [10] also observed a large reduction in fatigue performance of polyoxymethylene, polypropylene, and polycarbonate when a notch was introduced in these materials.

In general, cyclic frequency determines the failure mode of polymers during fatigue tests, which can be either a thermal failure or a fatigue failure [10-12]. However, the sensitivity to frequency depends on the polymer type. For example, polymethyl methacrylate and polyoxymethylene show strong sensitivity to frequency, while polyamide 6,6 and polycarbonate show little or no sensitivity to frequency. 


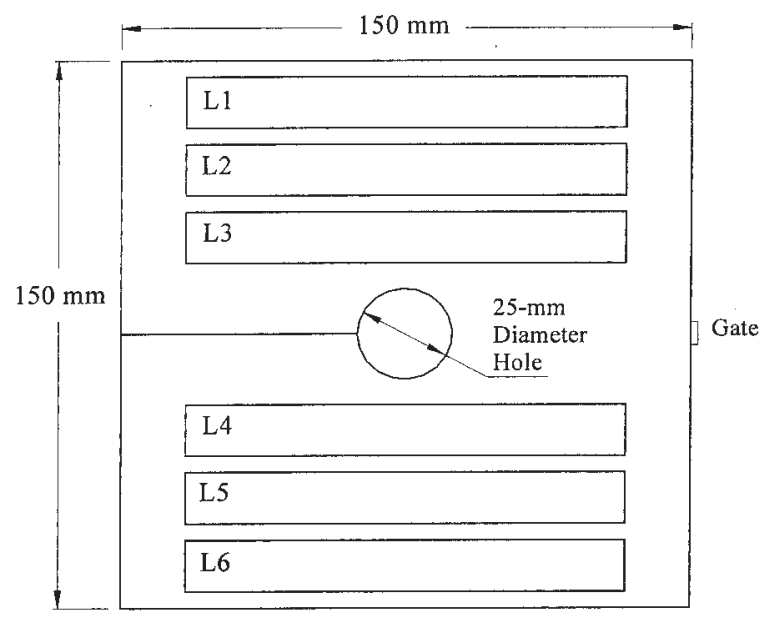

$\mathrm{L}$ (Flow direction)

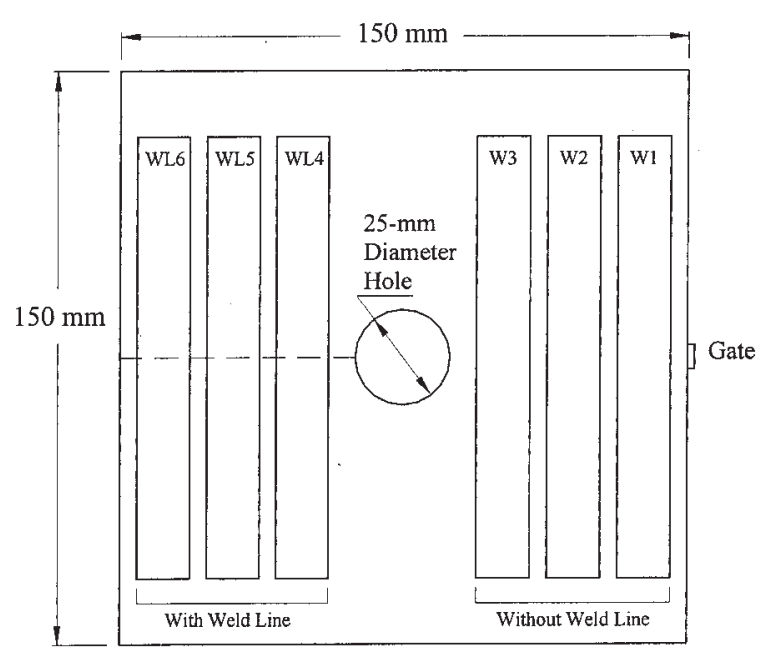

FIG. 1. Schematic of the injection molded plate showing the specimen locations $(\mathrm{L}=$ specimens in the flow direction, $\mathrm{W}=$ specimens normal to the flow direction, $\mathrm{WL}=$ specimens with the weld line).

Frequency also determines the stress level at which thermal failure occurs before fatigue failure. For example, in polyoxymethylene, thermal failure occurs at stress levels higher than 21.6 MPa if the frequency is $5 \mathrm{~Hz}$; however if the frequency is $1.7 \mathrm{~Hz}$, the threshold stress for thermal failure is $27.8 \mathrm{MPa}$ [10].

\section{EXPERIMENTAL}

The material investigated in this study was a $40 \mathrm{wt} \%$ talc-filled polypropylene homopolymer obtained from the Ferro Corporation. The trade name for this particular grade of talc-filled polypropylene was Ferro TP40AC52BK. The average flow rate of the material, as reported by Ferro, was $6.8 \mathrm{~g} / 10 \mathrm{~min}$. Square plates, $150 \mathrm{~mm} \times 150 \mathrm{~mm}$, were injection molded from the pellets of this material in a single edge-gated mold cavity with a central 25 -mm diameter steel core. A 90-ton injection molding machine was used to mold the plates. The plate thickness was $2.5 \mathrm{~mm}$. Dog-bone

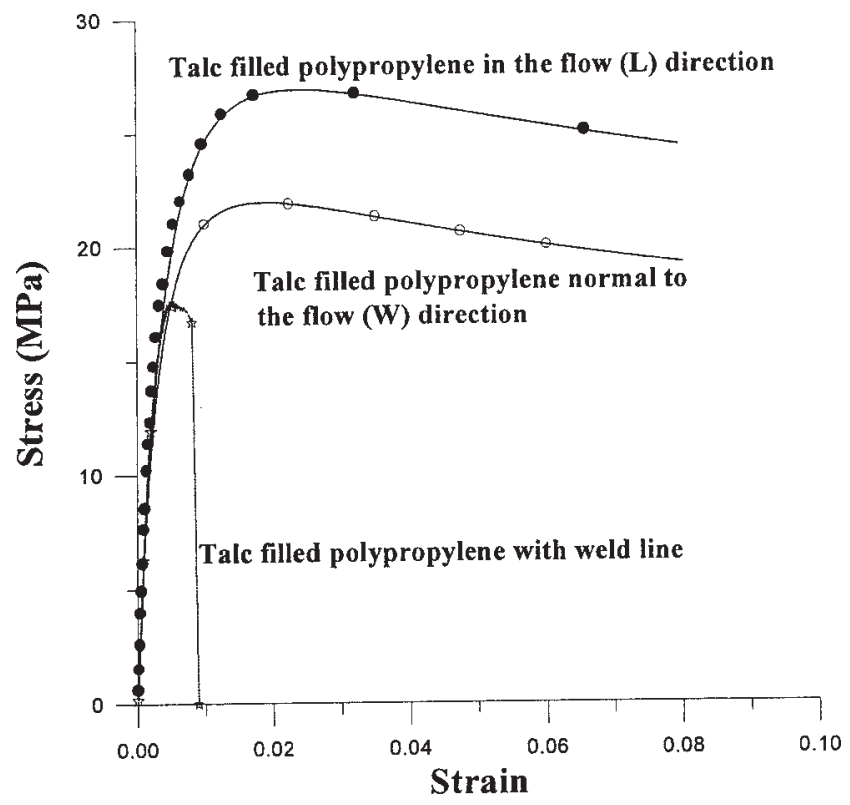

FIG. 2. Tensile stress-strain curves of $40 \mathrm{wt} \%$ talc-filled polypropylene in the flow direction, normal to the flow direction, and with the weld line.

shaped specimens were prepared from these plates in two different directions (Fig. 1), parallel to the flow direction (L-direction) and normal to the flow direction (W-direction). Specimens were also prepared from the welded zone, which was just behind the central hole in the plate. These specimens are referred to as the weld line (WL) specimens.

Both uniaxial tension tests and fatigue tests were performed on an MTS servohydraulic test machine. The specimen dimensions were $100 \mathrm{~mm}$ in overall length, $50 \mathrm{~mm}$ in gauge length, and $12.5 \mathrm{~mm}$ in gauge width. An extensometer (25 mm gauge length) was used to monitor strain during the tension tests. The crosshead speed was $1.25 \mathrm{~mm} / \mathrm{min}$, which was approximately equivalent to a strain rate of 0.05 $\min ^{-1}$. Elastic modulus $(E)$, yield strength $\left(\sigma_{y}\right)$, and yield strain $\left(\epsilon_{y}\right)$ were determined from the stress-strain curves. The elastic modulus was determined from the initial slope of the stress-strain diagram. The yield strength was defined at the maximum stress observed in the stress-strain curve and the corresponding strain was the yield strain.

Load-controlled fatigue tests were performed in the tension-tension mode at the ambient temperature (approximately $23^{\circ} \mathrm{C}$ ). The ratio of the minimum cyclic load and the

TABLE 1. Tensile properties of $40 \mathrm{wt} \%$ talc-filled polypropylene.

\begin{tabular}{lcccc}
\hline Material & $\begin{array}{c}\text { Strain rate } \\
\left(\mathrm{min}^{-1}\right)\end{array}$ & $\begin{array}{c}\text { Modulus } \\
(\mathrm{GPa})\end{array}$ & $\begin{array}{c}\text { Yield strength } \\
(\mathrm{MPa})\end{array}$ & $\begin{array}{c}\text { Yield strain } \\
(\%)\end{array}$ \\
\hline$L$-direction & 0.05 & 7.69 & 27.3 & 2.30 \\
$W$-direction & 0.05 & 7.43 & 22.2 & 1.71 \\
With weld line & 0.05 & 7.16 & 17.6 & 0.794 \\
With a 1.6 mm hole & 0.05 & - & 27.1 & 1.02 \\
With a 3.2 mm hole & 0.05 & - & 23.4 & 0.879 \\
With a 6.35 mm hole & 0.05 & - & 13.9 & 0.820 \\
\hline
\end{tabular}




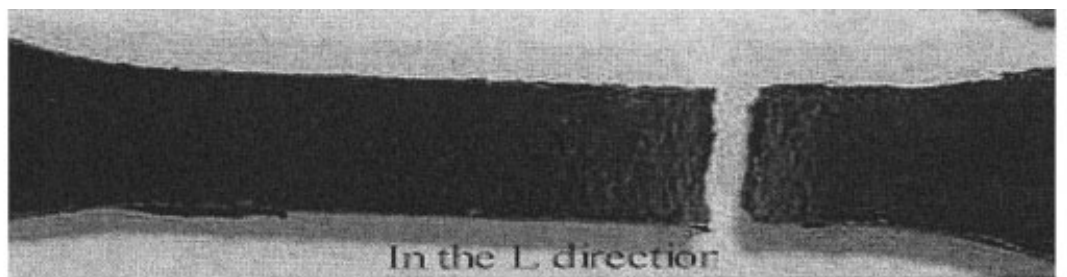

(a)

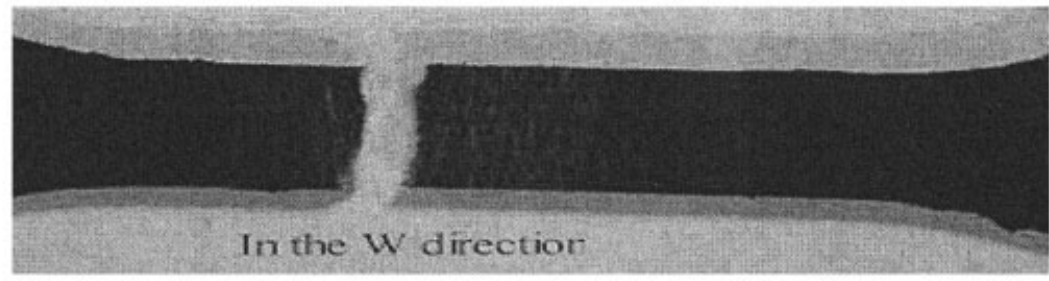

(b)

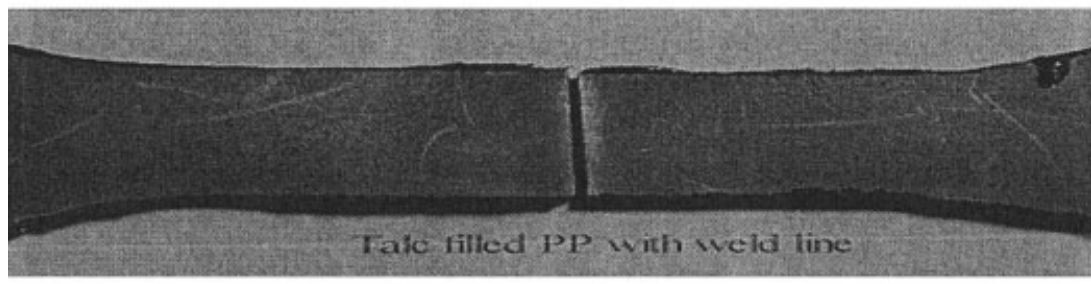

(c)
FIG. 3. Appearance of fractured tension specimen surfaces in the flow direction (a), normal to the flow direction (b), and with the weld line (c). maximum cyclic load, i.e., the R-ratio, was 0.1 . The maximum cyclic stress level for all three types of specimens ranged from 70 to $95 \%$ of the respective yield strength. The test frequency used for establishing the fatigue S-N diagrams was $1 \mathrm{~Hz}$. The stress concentration effect due to a central circular hole was studied with the L-direction specimens only. For this purpose, a circular hole of either 1.6 $\mathrm{mm}, 3.2 \mathrm{~mm}$, or $6.35 \mathrm{~mm}$ diameter was drilled at the center of the L-direction specimens. The theoretical stress concentration factors [13] corresponding to these hole diameters are 2.66, 2.43, and 2.16, respectively. The frequency effect was studied also with the L-direction specimens only. The maximum cyclic stress levels selected for these specimens were 80 and $85 \%$ of the yield strength. The test frequencies were $0.5,1,2,5,10$, and $20 \mathrm{~Hz}$.

\section{RESULTS}

\section{Tensile Properties}

Tensile stress-strain curves of talc-filled polypropylene in the $\mathrm{L}$ direction, the $\mathrm{W}$ direction and with a weld line are shown in Fig. 2. Three specimens were tested for each condition. The average mechanical properties obtained from these tests are listed in Table 1. From Fig. 2 and Table 1, it can be observed that the yield strength was higher in the L-direction than in the W-direction. The difference in properties in the L- and $\mathrm{W}$-directions is an indication that there was flow-induced anisotropy in the injection molded talcfilled polypropylene plates. The yield strength and yield strain of the weld line specimens were significantly lower than those for the L- and $\mathrm{W}$-direction specimens; however, the modulus was not affected by the presence of weld line. The weld line specimens also failed at a much lower strain than the other two types.

Figure 3 shows the surface appearance of the L-direction, $\mathrm{W}$-direction, and weld line specimens tested in tension. Fine crazes normal to the tensile stress axis were observed on the surfaces of the L- and W-direction specimens. The weld line specimen did not exhibit any such crazes. The scanning electron microscope (SEM) photographs of the fracture surfaces (Fig. 4) show the orientation of the talc particles in the L-direction, W-direction, and weld line specimens. In the L-direction specimens, the talc particles were largely oriented parallel to the flow direction, which was the same as the axial direction of the specimen. In the $\mathrm{W}$-direction specimen, a large number of talc particles can be seen to have orientation normal to the axial direction. In the weld 


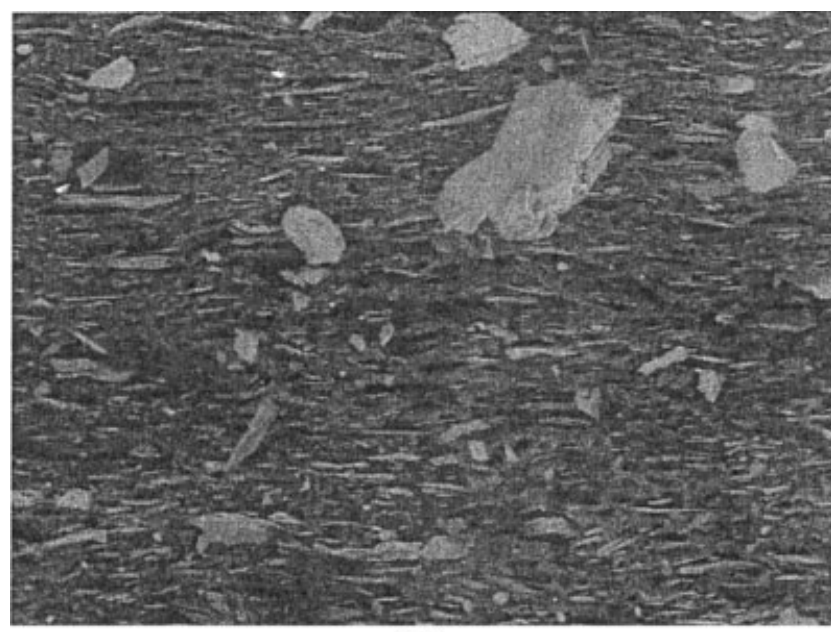

(a)

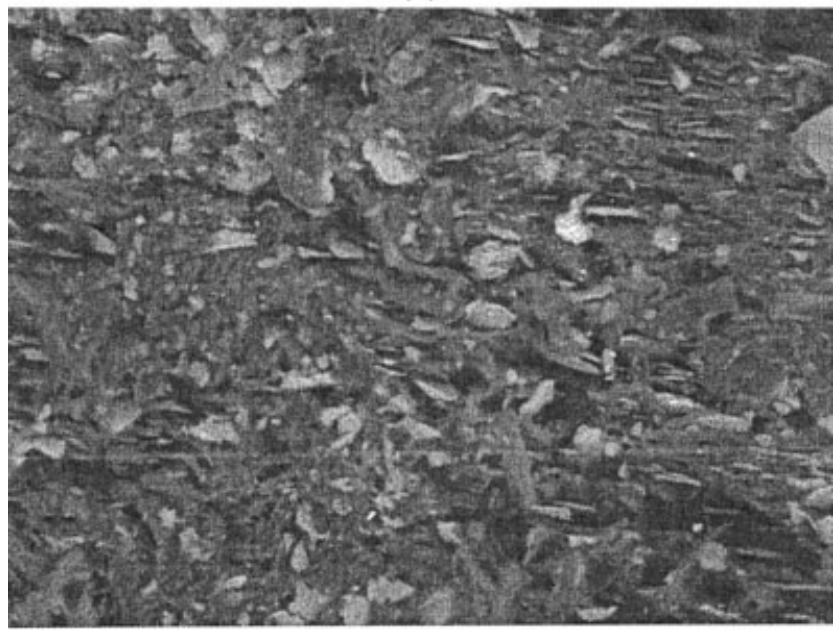

(b)

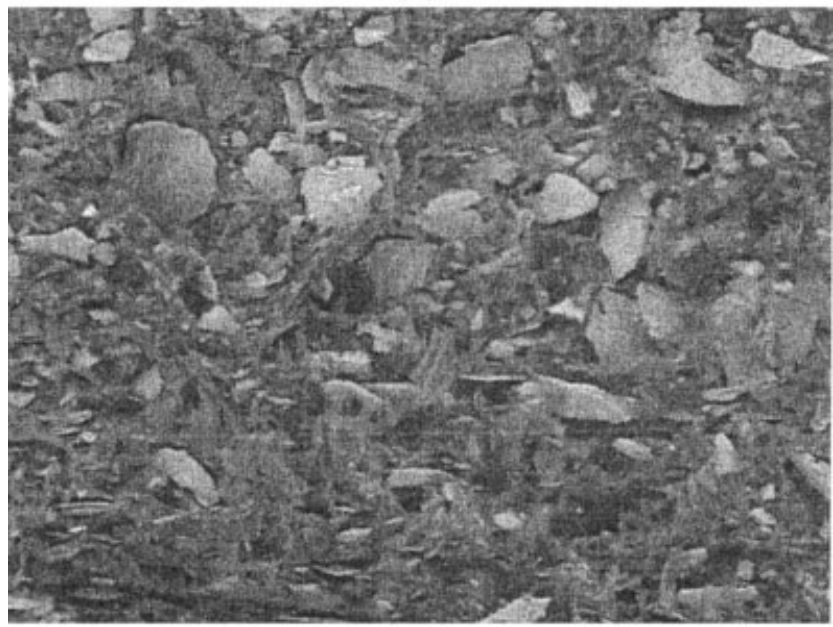

(c)

FIG. 4. Fracture surfaces of tension specimens in the flow direction (a), normal to the flow direction (b), and with the weld line (c).

line specimens, a large number of talc particles were oriented normal to the axial direction.

Table 1 gives the yield strengths and yield strains obtained with the L-direction specimens containing a central

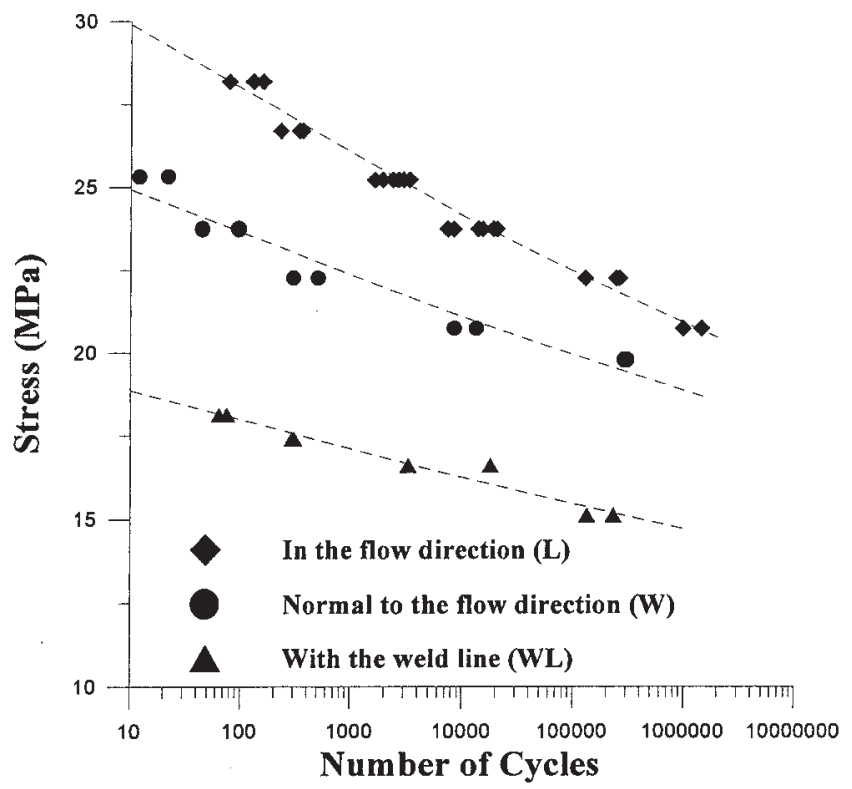

FIG. 5. S-N curves of $40 \mathrm{wt} \%$ talc-filled polypropylene in the flow direction, normal to the flow direction and with the weld line.

hole. The yield strength of the specimen with 1.6-mm hole was the same as that without any hole; however, as the hole diameter was increased, the yield strength decreased considerably with hole diameter. The yield strain showed a similar trend.

\section{Fatigue Properties}

Figure 5 shows the S-N curves of the talc-filled polypropylene in the flow (L) direction and normal to the flow (W) direction. In this figure, the vertical axis represents the maximum cyclic stress and the horizontal axis is the number of fatigue cycles to failure. As can be observed from Fig. 5, the fatigue strength of the talc-filled polypropylene in the L-direction was higher than that in the W-direction. However, the difference in fatigue strengths decreased at longer cycles. Figure 5 also shows the S-N curve for the specimens containing the weld line. These specimens showed the lowest fatigue strength. The fatigue strength of weld line specimens was nearly $50 \%$ lower than the L-direction specimens without weld line.

Based on the experimental results, the following equations were fitted to each of the S-N curves:

$$
\sigma=31.537\left(N_{f}\right)^{-0.029596} \quad \text { (In the flow direction) }
$$

$\sigma=26.37\left(N_{f}\right)^{-0.02429}$ (Normal to the flow direction)

$$
\sigma=19.82\left(N_{f}\right)^{-0.02156} \quad \text { (Weld line specimens) }
$$

Figure 6a shows the S-N curves of L-direction specimens containing a central hole. For comparison, the S-N 


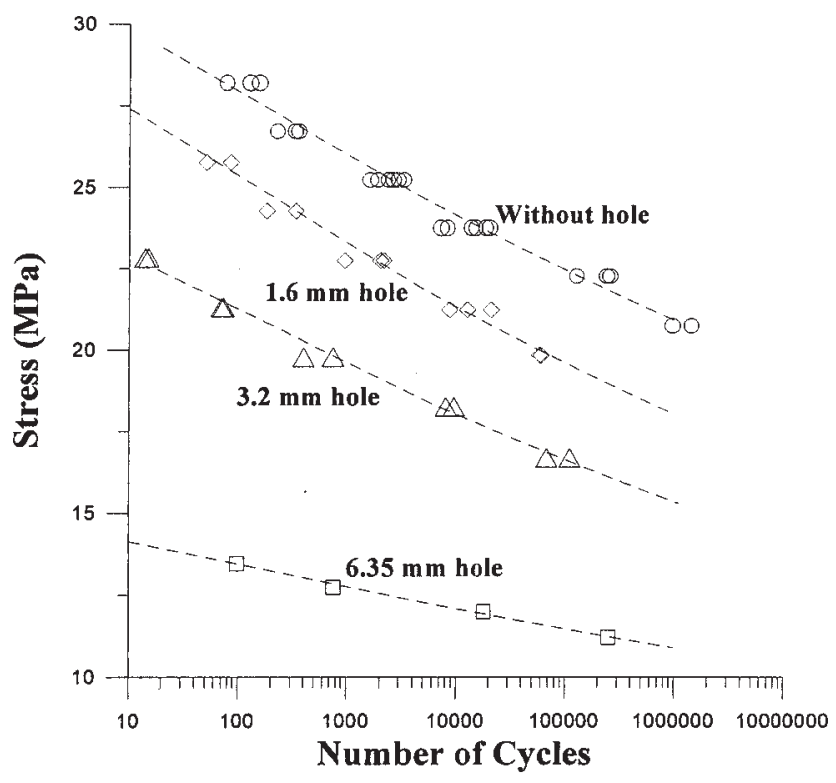

(a)

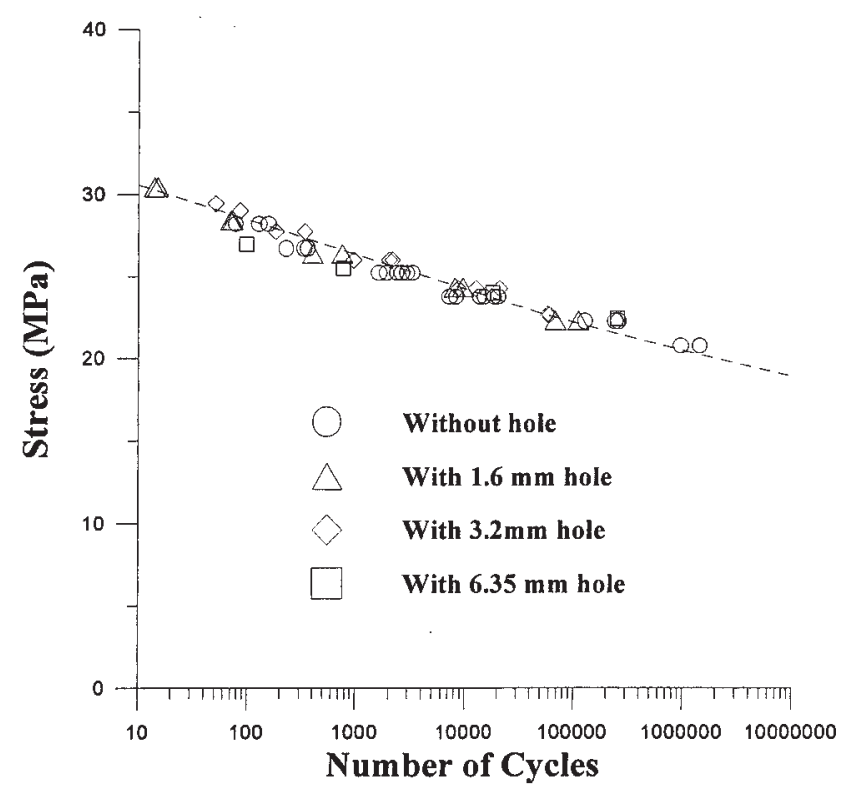

(b)

FIG. 6. S-N curves of $40 \mathrm{wt} \%$ talc-filled polypropylene with central hole: stress based on the gross area (a) and stress based on the net area at the hole (b).

curve for the unnotched L-direction specimen is also shown. In this figure, the stress for the notched specimens was calculated based on the gross area of the specimen. The fatigue strength was lower for specimens containing a central hole. Additionally, the fatigue strength decreased with increasing hole diameter. However, when the stress was calculated based on the net area, the S-N curves for unnotched and all three notched specimens merged into one S-N curve, indicating that the fatigue

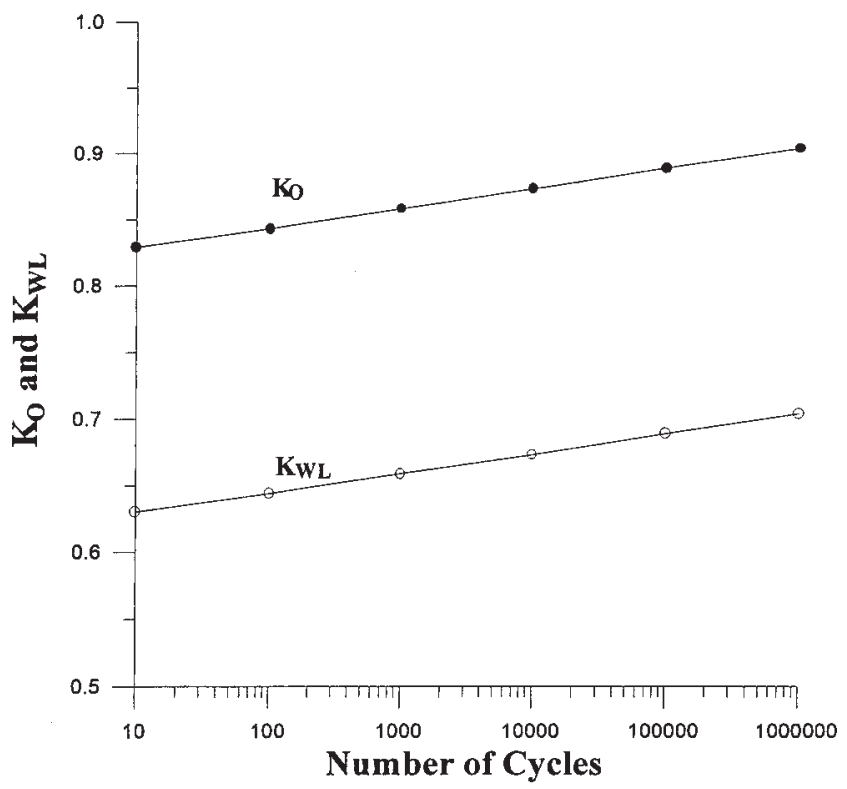

FIG. 7. Orientation factor $\left(\mathrm{K}_{\mathrm{o}}\right)$ and weld line factor $\left(\mathrm{K}_{\mathrm{WL}}\right)$.

strength of talc-filled polypropylene was relatively insensitive to stress concentration.

The effect of stress concentration on the fatigue strength of metals [14] is often determined using the fatigue stress concentration factor $\mathrm{K}_{\mathrm{t}}$, which is defined as

$K_{f}$

$=\frac{\text { Fatigue strength without a geometric discontinuity at } N \text { cycle }}{\text { Fatigue strength with a geometric discontinuity at } N \text { cycle }}$.

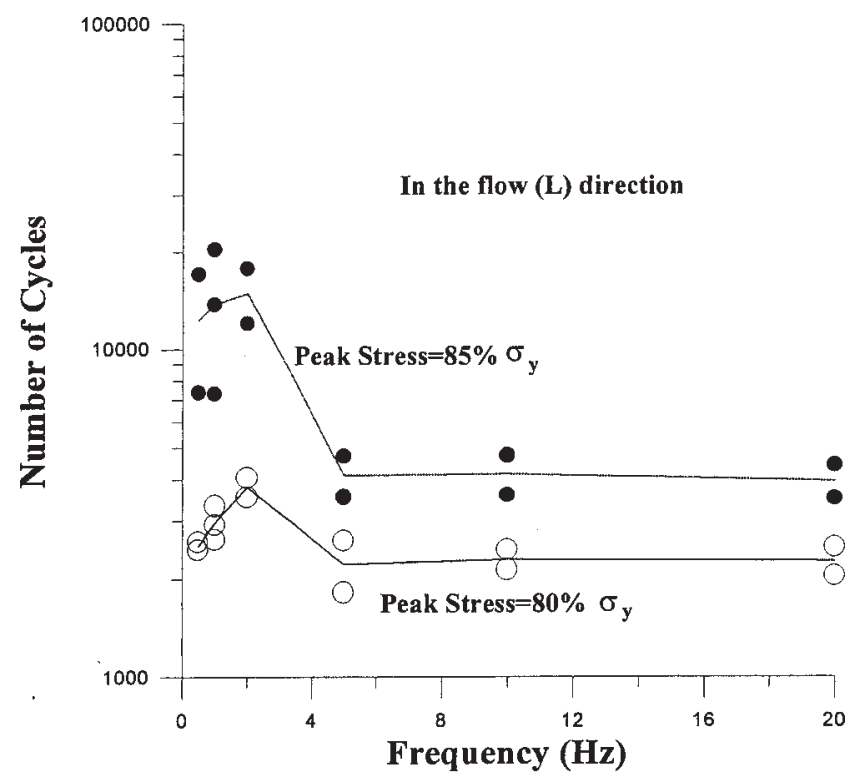

FIG. 8. Effect of cyclic frequency on the fatigue life of $40 \mathrm{wt} \%$ talc-filled polypropylene. 


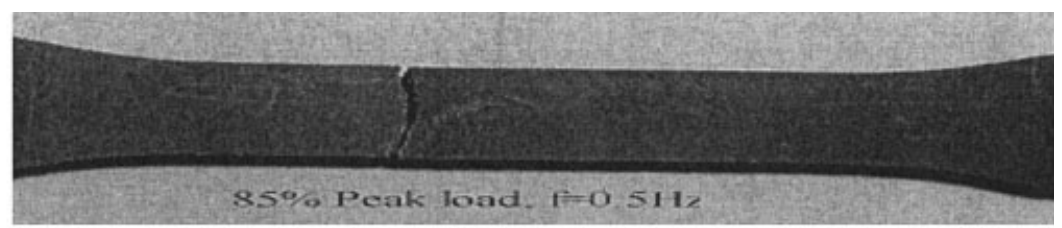

(a)

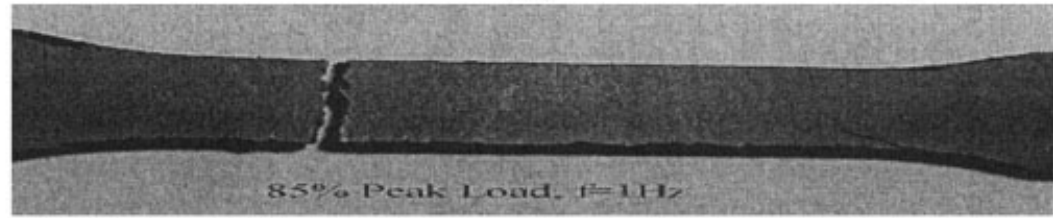

(b)

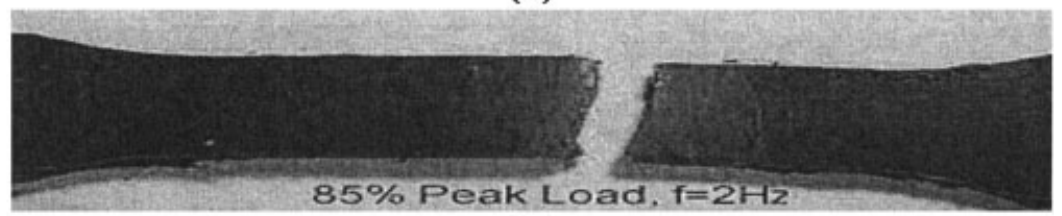

(c)

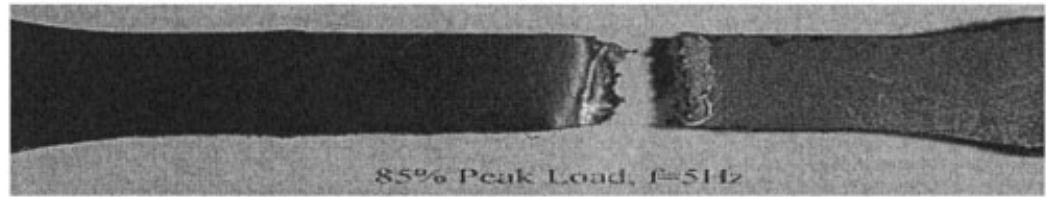

(d)

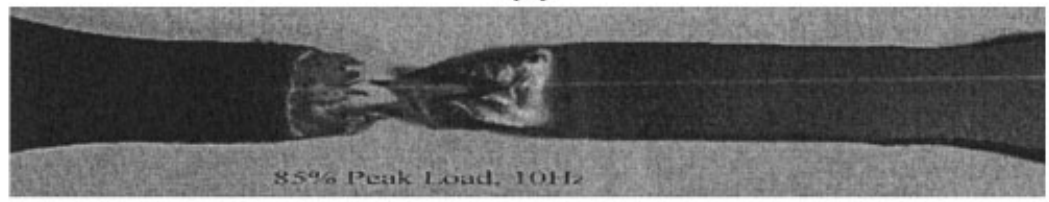

(e)

FIG. 9. Photographs of $40 \mathrm{wt} \%$ talc-filled polypropylene fatigue specimens tested at different cyclic frequencies and at peak fatigue load equivalent to $85 \%$ of the yield strength. a: $0.5 \mathrm{~Hz}$; b: $1 \mathrm{~Hz} ; \mathrm{c}: 2 \mathrm{~Hz}$; d: 5 $\mathrm{Hz}$; e: $10 \mathrm{~Hz}$; : $20 \mathrm{~Hz}$.

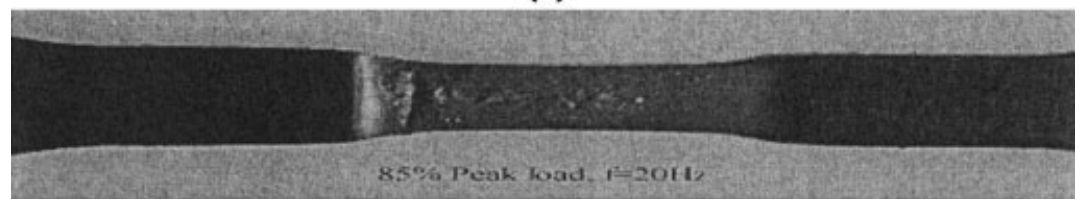

(f)

$\mathrm{K}_{\mathrm{f}}$ is related to the theoretical stress concentration factor $\mathrm{K}_{\mathrm{t}}$ by the following equation:

$$
K_{f}=1+q\left(K_{t}-1\right)
$$

where $\mathrm{q}$ is called the notch sensitivity factor, which depends on the notch radius and the tensile strength of the material. For many metals, $0 \leq \mathrm{q} \leq 1$ due to local yielding at the notch root during fatigue loading. For a notch insensitive material, $\mathrm{q}=0$, and for a highly notch sensitive material, $\mathrm{q}$ approaches unity.

Based on the net area at the hole, hole radius in the range of 1.6 to $6.35 \mathrm{~mm}$ did not cause any deterioration in the fatigue strength of $40 \mathrm{wt} \%$ talc-filled polypropylene. Thus, for this material, $\mathrm{K}_{\mathrm{f}} \approx 1$ and $\mathrm{q} \approx 0$, which means the talc-filled polypropylene can be considered notch insensitive. However, the notch insensitivity, in this case, was not due to large scale yielding. Instead, the reason for notch insensitivity can be that the inherent flaw size in the material was smaller than the hole radius, and therefore the hole size did not control the fatigue life. Typically, the inherent flaw size in such a material will be the mean radius of the filler, which for talc particles is typically in the range of $1-10 \mu \mathrm{m}$.

Based on the fatigue strength data of normal to the flow direction (W) and weld line (WL) specimens relative to the flow direction (L) specimens, it is possible to define an orientation factor $\left(\mathrm{K}_{\mathrm{O}}\right)$ and a weld line factor $\left(\mathrm{K}_{\mathrm{WL}}\right)$ that can be used for fatigue design purposes. They are defined as follows:

$$
K_{O}=\frac{\text { Fatigue Strength Normal to the Flow Direction }}{\text { Fatigue Strength in the Flow Direction }}
$$




$$
K_{W L}=\frac{\text { Fatigue Strength of the Weld Line }}{\text { Fatigue Strength in the Flow Direction }} .
$$

The orientation factor and the weld line factor are plotted in Fig. 7 as a function of number of cycles. Both factors increase with increasing number of cycles, indicating that the sensitivity to these factors decreases at longer lives. Furthermore, the weld line factor was smaller than the orientation factor, indicating that weld line caused a greater reduction in fatigue strength than the flow induced filler orientation.

\section{Effect of Cyclic Frequency on Fatigue}

The frequency effect on fatigue life of $40 \mathrm{wt} \%$ talc-filled polypropylene is shown in Fig. 8. In this case, the fatigue specimens were in the L-direction and the fatigue stress levels were $80 \%$ and $85 \%$ of the yield strength of the L-direction specimens. At these two stress levels, the fatigue life showed an increase with increasing frequency up to $2 \mathrm{~Hz}$. Above $2 \mathrm{~Hz}$, the fatigue life decreased but attained a constant value above $5 \mathrm{~Hz}$.

Figure 9 shows photographs of failed fatigue specimens tested at different frequencies. Fatigue failure was observed in specimens tested at $0.5,1$, and $2 \mathrm{~Hz}$. In specimens tested at 5,10 , and $20 \mathrm{~Hz}$, thermal failure, in the form of softening and melting, occurred instead of fatigue failure. Due to thermal softening, the elongation increased with cycling, and in some specimens, excessive deformation was accompanied with necking. Failure by separation in some of these specimens occurred in highly thinned areas. At high frequencies, the temperature was high enough to cause melting of the polypropylene matrix, which can be seen in Fig. 9d-f.

\section{CONCLUSIONS}

In this paper, it was shown that injection molding caused a significant amount of anisotropy in both static and fatigue properties of $40 \mathrm{wt} \%$ talc-filled polypropylene. Both tensile and fatigue strengths of the material in the flow direction were higher than those normal to the flow direction. The presence of weld line also caused a severe reduction in tensile strength, elongation, and fatigue strength. However, this material did not show any notch sensitivity in fatigue. Finally, the test frequency was shown to influence the failure mode in fatigue.

\section{REFERENCES}

1. J.L. Broge, Automotive Eng. International, 108, 70 (2000).

2. J.E. Stamhuis, Polym. Comp., 5, 202 (1984).

3. J.E. Stamihus, Polym. Comp., 9, 72 (1988).

4. Y. Zhou and P.K. Mallick, Polym. Eng. Sci., 42, 2449 (2002).

5. T. Tjäder, J. Seppälä, and P. Jääskeläinen, J. Mat. Sci., 33, 923 (1998).

6. J.K. Kim, S.H. Park, H.T.O, and H.K. Jeon, Polymer, 42, 2209 (2001).

7. D. Jarus, J.W. Summers, A. Hiltner, and E. Baer, Polymer, 41, 3057 (2000).

8. R. Boukhili, R. Gauvin, and M. Gosselin, Development and Design With Advanced Materials, Elsevier Science Pub., 267 (1990).

9. L.J. Wolf and W.B. Diboll, Jr., J. Eng. Industry, Trans. ASME, 319 (1965).

10. R.J. Crawford and P.P. Benham, Polymer, 16, 908 (1975).

11. R.W. Hertzberg and J. A. Manson, Fatigue of Engineering Plastics, Academic Press, New York (1980).

12. J.A. Sauer and G.C. Richardson, Intl. J. Frac., 16, 499 (1980).

13. R.J. Roark and W.C. Young, Formulas for Stress and Strain, 5th ed., McGraw-Hill, New York (1975).

14. J.A. Bannantine, J.J. Comer, and J.L. Handrock, Fundamentals of Metal Fatigue Analysis, Prentice Hall, New Jersey (1990). 